\title{
Late transmural mesh migration into the esophagus after Nissen fundoplication
}
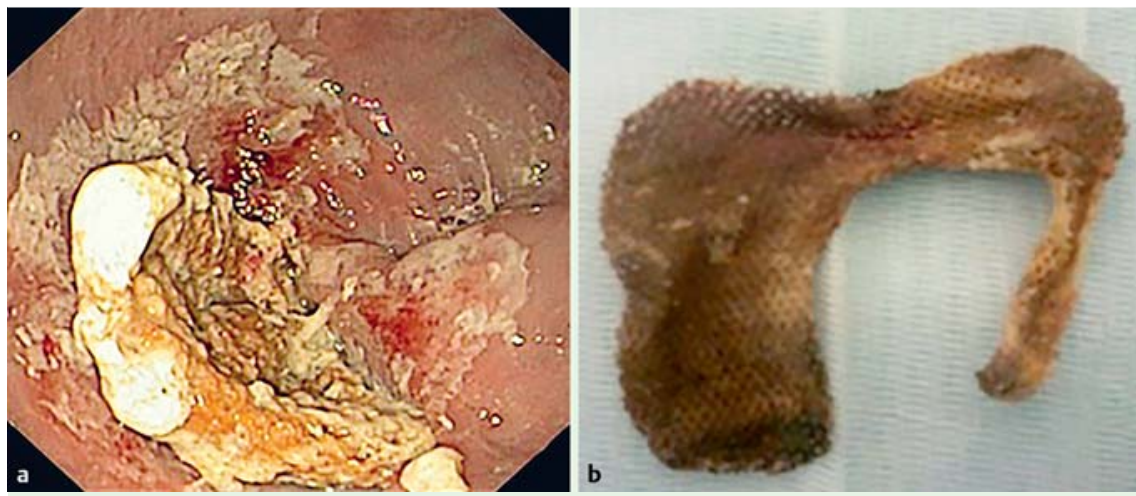

Fig. 1 The foreign body that was obstructing the esophageal lumen: a seen endoscopically; b following its extraction, when it was revealed to be a surgical mesh.
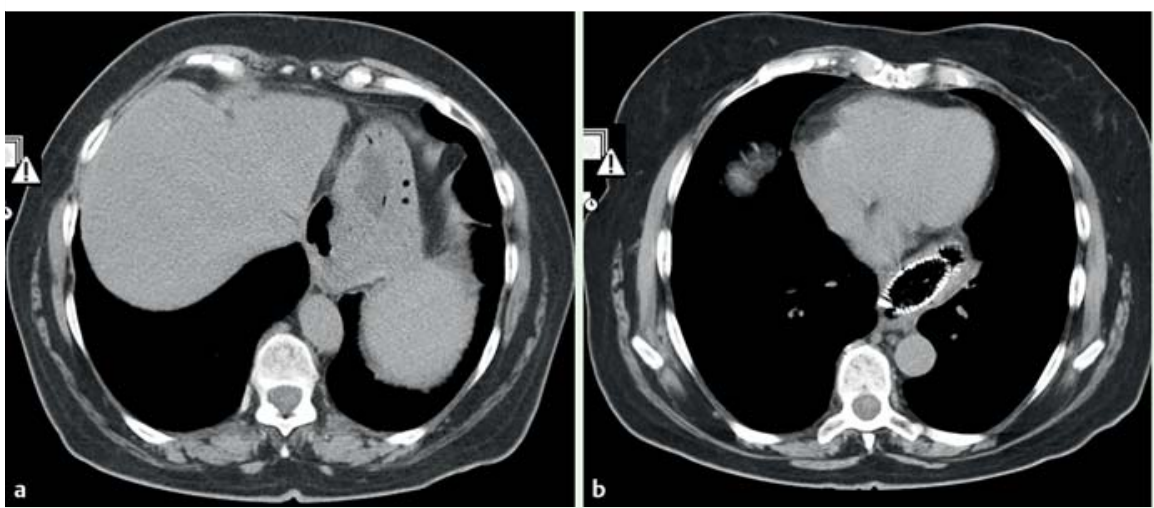

Fig. 3 Computed tomography (CT) images showing: a an intra-abdominal air collection at the level of the fundoplication and an esophagogastric fistula; b a covered self-expanding metal stent in position to treat both the esophageal stricture and the fistula; $\mathbf{c}$ a reduction in the size of the intra-abdominal air collection after removal of the stent and healing of the fistula 6 weeks later.

A 71-year-old woman was referred to the gastroenterology department with progressive dysphagia and weight loss over 4 weeks. She had undergone a laparoscopic fundoplication with closure of the hiatal crura with mesh 5 years previously for heartburn due to gastroesophageal reflux disease and a large hiatal hernia.

Upper gastrointestinal endoscopy showed an irregularly shaped foreign body obstructing the lumen immediately proximal to the cardia ( Fig.1a). This was assumed to be a food bolus, so the object was extracted using a Roth net standard retriever. Surprisingly, the foreign body proved to be a surgical mesh ( $\mathbf{F i g . 1} \mathbf{b}$ ). The esophageal wall was again inspected after this endoscopic extraction. There was evidence of severe lumen tortuosity and ulcerated stenosis at the gastroesoph- ageal junction, and the opening of a fistula was found $1 \mathrm{~cm}$ above the cardia on the anterior wall of the esophagus ( $\bullet$ Fig. 2 ). Thoracoabdominal computed tomography (CT) scanning confirmed an intraabdominal air collection at the level of the fundoplication and a line of air to the esophagogastric fistula ( $\bullet$ Fig.3a). A covered self-expanding metal stent (Hanarostent; $80 \times 14 \mathrm{~mm}$ ) was inserted to treat both the esophageal stricture and the fistula ( $\bullet$ Fig.3b). There were no complications during the procedure, following which the patient reported no dysphagia (grade 0 ).

The stent was removed 6 weeks later without complications and complete healing of the fistula was confirmed. A further CT scan showed reduction of the intra-abdominal air collection ( $\bullet$ Fig. $3 c$ )
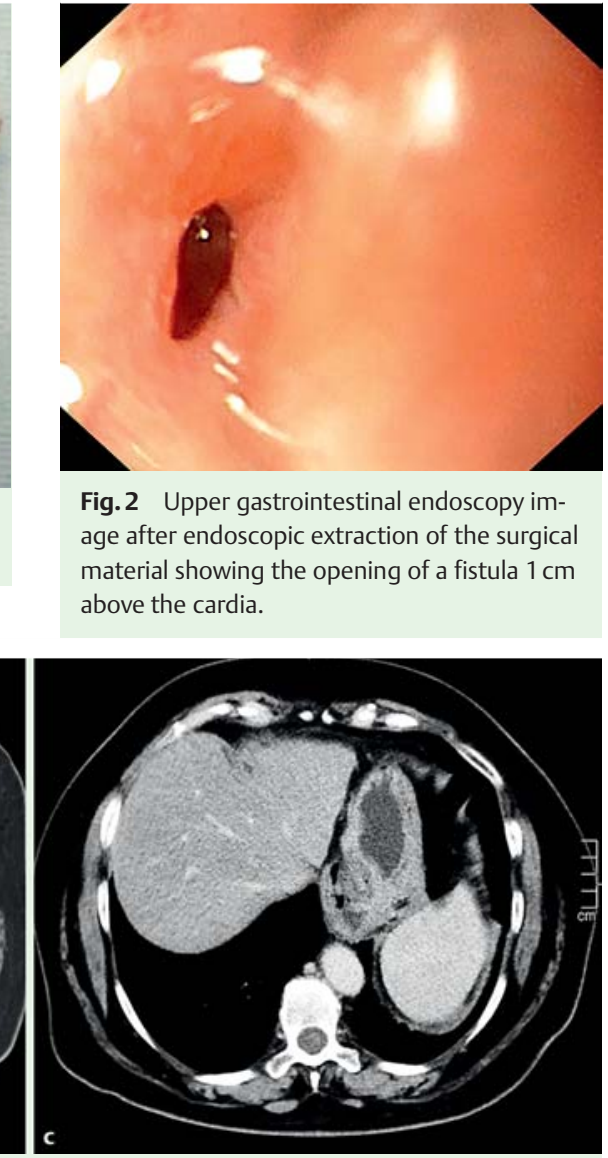

Fig. 2 Upper gastrointestinal endoscopy image after endoscopic extraction of the surgical material showing the opening of a fistula $1 \mathrm{~cm}$ above the cardia.

with the patient reporting weight gain and no symptoms of dysphagia.

Closure of the hiatal crura has proven to be a fundamental issue in laparoscopic antireflux surgery [1]. Mesh reinforcement is not without complications and the incidence of these complications may be greater than previously reported $[2,3]$. We describe a rare case of dysphagia caused by an esophagogastric fistula that was secondary to complete transmural esophageal migration of the surgical mesh 5 years after Nissen fundoplication and was resolved by endoscopic management.

Endoscopy_UCTN_Code_CPL_1AM_2AF

Competing interests: None 
Cátia Leitão, Helena Ribeiro,

Ana Caldeira, Rui Sousa,

António Banhudo

Department of Gastroenterology, Amato-Lusitano Hospital, Castelo Branco, Portugal

\section{References}

1 Soricelli E, Basso N, Genco A et al. Long-term results of hiatal hernia mesh repair and antireflux laparoscopic surgery. Surg Endosc 2009; 23: 2499-2504

2 Stadhuber RJ, Sherit AE, Mittal SK et al. Mesh complications after prosthetic reinforcement of hiatal closure: a 28 cases series. Surg Endosc 2009; 23: 1912 - 1226

3 Frantzides CT, Madan AK, Carlson MA et al. A prospective, randomized trial of laparoscopic polytetrafluoroethyleno patch repair vs. simple cruroplasty for large hiatal closure. Arch Surg 2002; 137: 649-652
Bibliography

DoI http://dx.doi.org/

10.1055/s-0042-105646

Endoscopy 2016; 48: E166-E167

(C) Georg Thieme Verlag KG

Stuttgart · New York

ISSN 0013-726X

Corresponding author

\section{Cátia Leitão, MD}

Department of Gastroenterology Amato-Lusitano Hospital

Avenida Pedro Álvares Cabral 6000-085 Castelo Branco

Portugal

Fax: +351-272-000257

catia.f.leitao@gmail.com 